\title{
Effects of Different Substrates on Rectangular Microstrip Patch Antenna for X-band
}

\author{
Imran Khan ${ }^{1}$, D. Geetha Devanagavi ${ }^{2}$ K. R. Sudhindra ${ }^{3}$, S. Prathibha ${ }^{4}$, C. Shruthi ${ }^{5}$ and S. Nirmala ${ }^{6}$ \\ ${ }^{1 \& 2}$ School of Electronics and Communication Engineering, REVA University, Bangalore, Karnataka, India \\ ${ }^{3}$ Departmentof Electronics and Communication Engineering, BMSCE, Bangalore, Karnataka, India \\ ${ }^{4,5 \& 6}$ Department of Electronics and Communication Engineering, Government Engineering College, Karnataka, India \\ E-Mail: imrangce@gmail.com
}

\begin{abstract}
In this paper, the performance of Microstrip Patch Antenna (MSPA) is analyzed by changing the substrate materials. MSPA is designed to operate with the fixed dimensions of $32 \times 26 \times 1.6 \mathrm{~mm}^{3}$ for three substrate materials. A comparison has been done in terms of reflection coefficient $\left(S_{11}\right)$, gain, efficiency $(\eta)$, radiation pattern and cost. The simulated results show very good performance with TLC substrate as compared to FR4 and RT Duroid by showing good radiation efficiency for all the three bands viz 7.0, 9.6 and 10.8 GHz with the efficiency of $99 \%, 99 \%$ and $96 \%$ respectively, stable radiation patterns, gain of 1.32, 1.81 and $2.0 \mathrm{~dB}$. FR-4 and RT Duroid produces two bands each of 8.4/9.6 GHz and 11.1/12.0 GHz respectively which shows a gain of 1.29/1.36 dB for FR4 and 1.04/7.95 dB for RT Duroid along with efficiency of $68 \% / 60 \%$ and $96 \% / 96 \%$ respectively with acceptable bandwidth. . The Antenna is simulated using HFSS simulator solution software.

Keywords: ANSYS HFSS, Dielectric Constant, Current Distribution, Radiation Pattern
\end{abstract}

\section{INTRODUCTION}

An Antenna is a transducer that proselytes radio frequency (RF) fields into substituting current or the other way around. There are both getting and transmission reception apparatuses for sending or accepting radio waves transmissions. Radio waves are electromagnetic waves that bring signals through air at the speed of light with no transmission misfortune. Antenna can be Omni-directional, directional or self-assertive. Antennas assume an imperative job in the activity of all radio hardware. They are utilized in WLAN, versatile communication and satellite correspondence. In the present time, the upgraded innovation of wireless communication is increment step by step according to the necessities. In imminent to security perspective, wireless communications are utilized in programmed association and company. Wireless communication systems are used to transmit images andvideos with higher data rates [1]. For any wireless communication, the antenna plays a v ery vital role. The demand of the wireless technology is reduced antenna size with high performance, low return loss and high bandwidth [2]. $\mathrm{X}$ band, radar applications from 8 to $12 \mathrm{GHz}$ in $\mathrm{X}$ band, and to cover $\mathrm{X}$ band uplink frequency band from $8 \mathrm{t} \mathrm{o} \quad 8.4 \mathrm{GHz}$ as assigned by the International Telecommunications Union (ITU) [3]. The meaning of an antenna as indicated by IEEE standard 145-1983 is that it is a methods for emanating and getting the radio waves (or) extensively it is likewise characterized as a transducer which changes over voltage and current on a transmission line into electromagnetic field in space. A receiving antenna changes electromagnetic vitality into electric or attractive vitality. A transmitting antenna changes the vitality from electric or attractive into electromagnetic energy [4]. MSPAs are depicted by a broad number of physical parameter than microwave antennas [5]. MSPA emanates primarily because of the flanking field between the fix edge and ground plane, for good execution, a thick dielectric substrate having low dielectric value is basic since it gives better radiation and better capability. In any case such an ordinary plan prompts a g reater size of the miniaturized MSPA. Substrates with higher dielectric constants must be used which is less compelling and result in thin information exchange capacity. Subsequently an exchange - off must be acknowledged between the MSPA execution and measurement [6]. Microstrip antennas are having minimal effort and also light weight which makes them very helpful for the wireless communication purpose [7].

In this present investigation three different substrate materials are considered with their respective properties. The dielectric substrates used are FR4 with permittivity 4.4, Taconic with permittivity 3.2 and RT- Duroid with permittivity 2.2 . The height of the substrates is $1.6 \mathrm{~mm}$. Different parameters such as VSWR, Return Loss, Antenna Gain, Directivity, Antenna Efficiency and Bandwidth are analysed by simulating the calculated dimensions on above said three different substrates. A basic structure designed of microstrip patch antenna is illustrated in Figure 1 which utilizes a square patch with dimensions indicated in Table I.

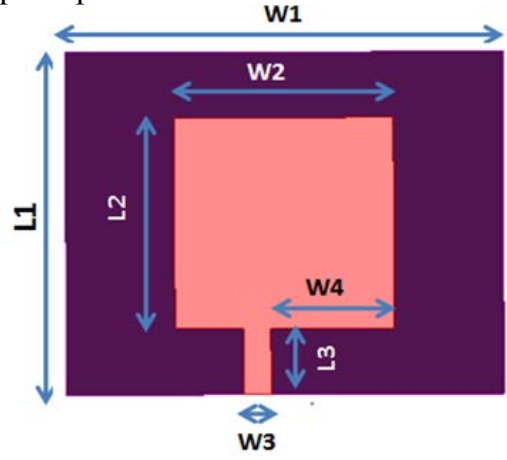

Fig. 1 Structure of the MSPA 
TABle I DetAILED DimEnsions Of THE ANTENNA

\begin{tabular}{|c|c|}
\hline Parameters & $\begin{array}{c}\text { Dimensions } \\
\text { (mm) }\end{array}$ \\
\hline W1 & 32 \\
\hline W2 & 16 \\
\hline W3 & 2 \\
\hline W4 & 9 \\
\hline L1 & 26 \\
\hline L2 & 16 \\
\hline L3 & 5 \\
\hline
\end{tabular}

\section{ANTENNA DESIGN AND ANALYSIS}

The proposed antenna framework and its point by point dimensional configurations are exhibited in Figure 1 a nd Table 1. The antenna contains a square patch. The square shaped patch is in charge of the resonating frequencies at 8.4 and $9.6 \mathrm{GHz}$ for FR4 (dual band), 11.1 and $12.0 \mathrm{GHz}$ for RT Duroid (dual band) and 7.0, 9.6 and $10.8 \mathrm{GHz}$ for TLC (triple band) substrate. The general impedance organizing of $50 \Omega$ is given by microstrip line (L3XW3) using lumped port excitation. The outline and reproduction of these structures are completed in ANSYS High Frequency Structure Simulator (HFSS) v.13.0 simulating software. The substrate utilized for the recreation is FR4, RT Duroid and Taconic which has a thickness of $1.6 \mathrm{~mm}$. The emanating part comprises of square patch $(\mathrm{L} 2 \times \mathrm{W} 2)$. The square patches influences the current distribution of the transmitting surface, thereby expanding absolute current length path, because of which antenna radiates at in excess of one band. The effect of square patch on current distribution is illustrated in Figures 2, 3 and 4 for all the three antennas i.e. FR4, RT Duroid, and Taconic substrates respectively.
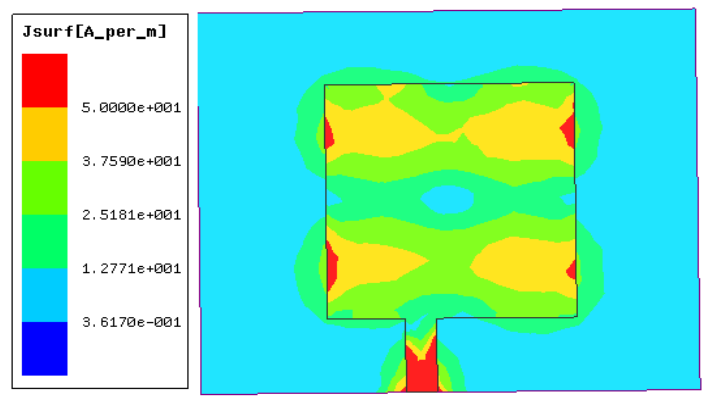

(a)
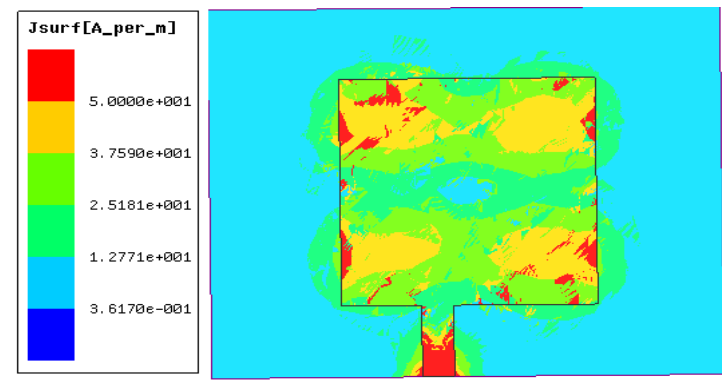

(b)

Fig. 2 Current Distribution for FR4 at (a) 8.4 and (b) $9.6 \mathrm{GHz}$
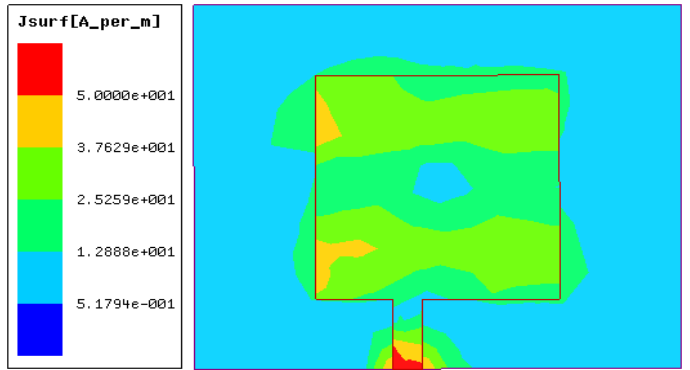

(a)
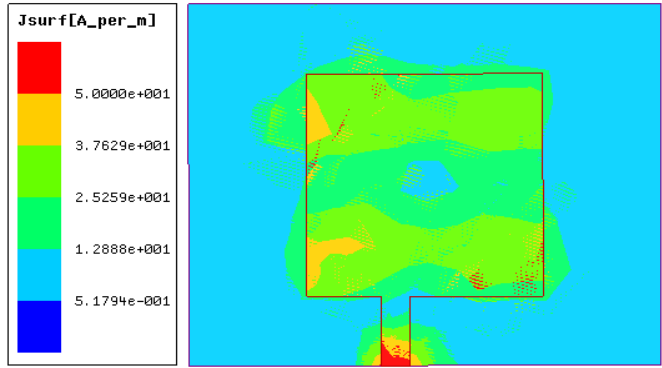

(b)

Fig. 3 Current Distribution for RT DUROID at N (a) 11.1 and (b) $12.0 \mathrm{GHz}$
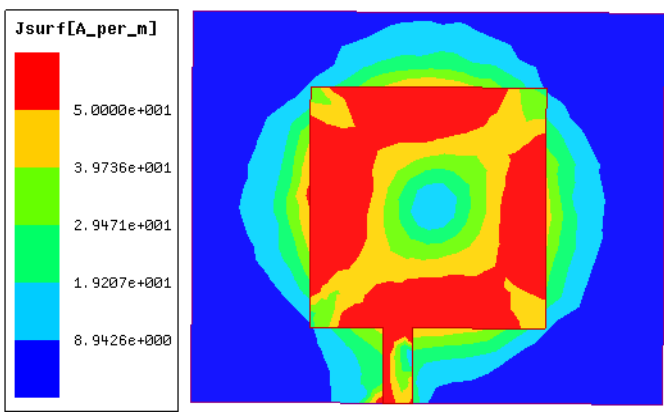

(a)
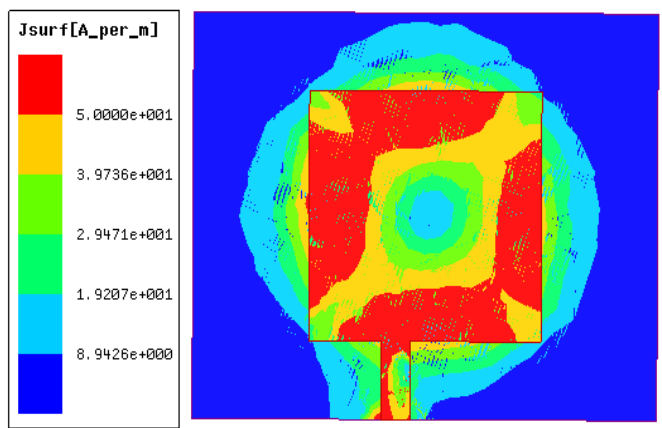

(b)
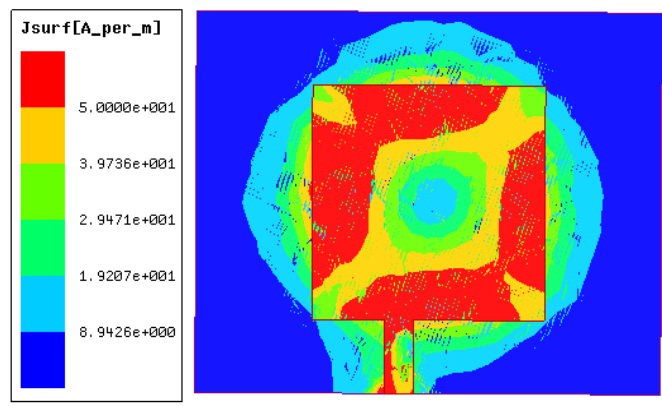

(c)

Fig. 4 Current Distribution for TLC at (a) 7.0 (b) 9.6 and (c) $10.8 \mathrm{GHz}$ 


\section{RESULTS AND DISCUSSION}

The Antenna simulations are carried out using the finite element method (FEM) based electromagnetic (EM), Ansoft's HFSS. Simulated results of all the three antennas using FR4, RT Duroid and Taconic substrates are illustrated below figures. Figure 5 de picts the simulated $\mathrm{S}_{11}$ of the antenna for FR4 substrate. The antenna has two bands at 8.4 and $9.6 \mathrm{GHz}$ with a $\mathrm{S}_{11}$ bandwidth of about 3.59 and $2.08 \%$ under simulation. The radiation pattern measured for the antenna proposed at 8.4 and $9.6 \mathrm{GHz}$ is illustrated in Figure 6.

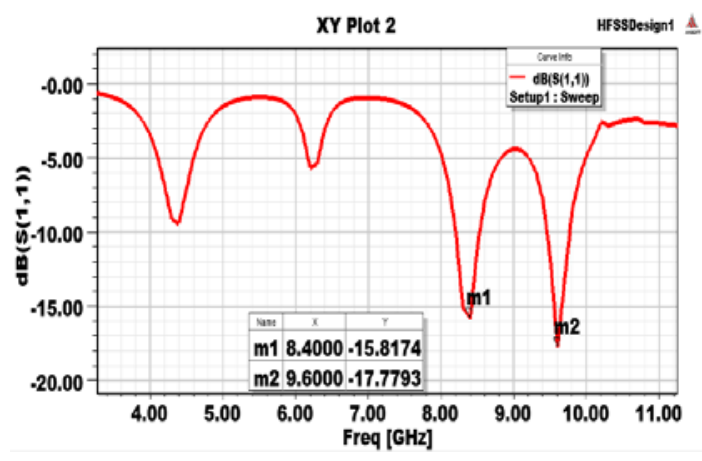

Fig. 5 Simulated Reflection Coefficient of FR4 Substrate

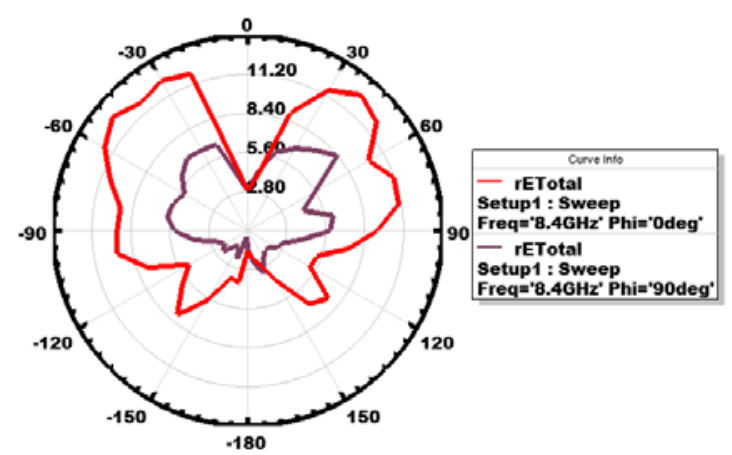

(a)

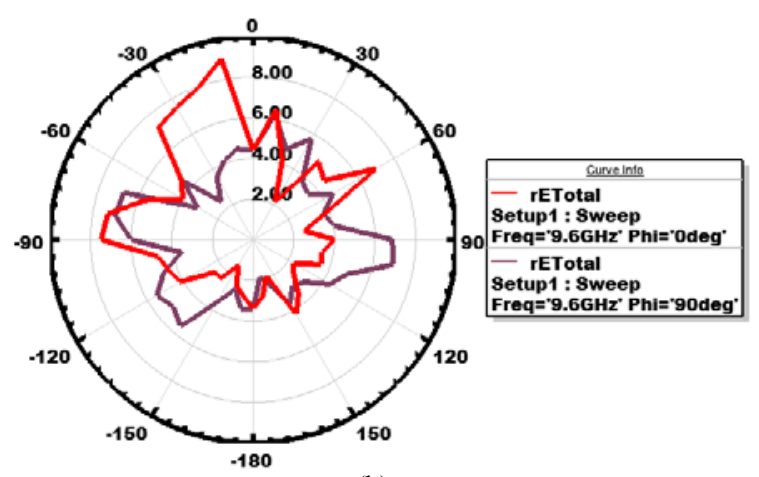

(b)

Fig. 6 Simulated Radiation Pattern of RT DuroidSubstrate at (a) 8.4 and (b) $9.6 \mathrm{GHz}$

Figure 7 depicts the simulated $S_{11}$ of the antenna for RT Duroid substrate. The antenna has two bands at 11.1 and $12.0 \mathrm{GHz}$ with a $\mathrm{S}_{11}$ bandwidth of about 9.67 and $5.04 \%$ under simulation. The measured radiation pattern of the proposed antenna at 11.1 and $12.0 \mathrm{GHz}$ is illustrated in Figure 8.

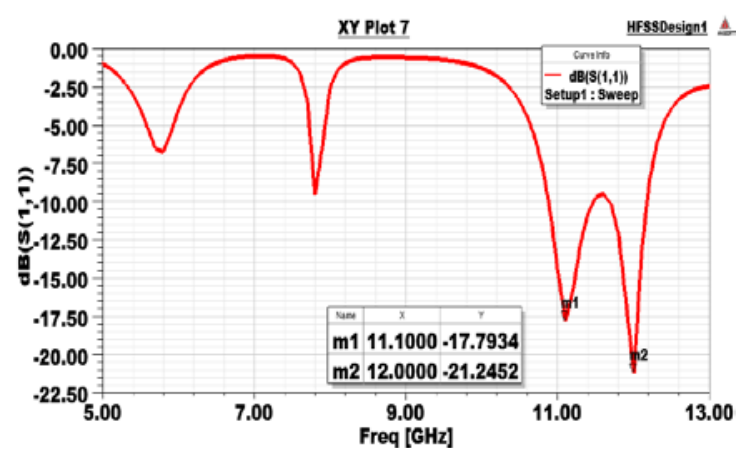

Fig. 7 Simulated Reflection Coefficient of RT DuroidSubstrate

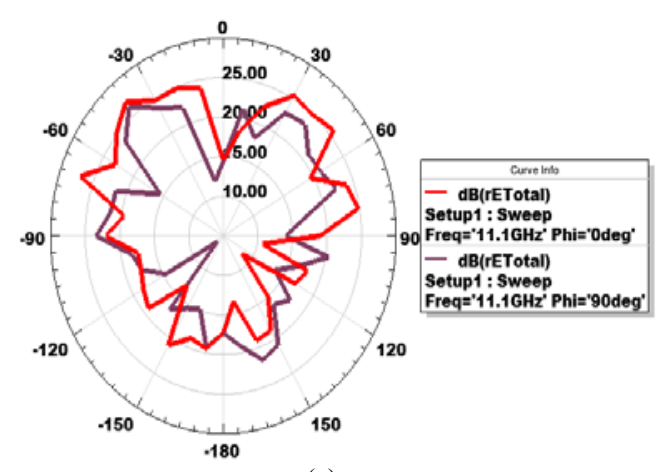

(a)

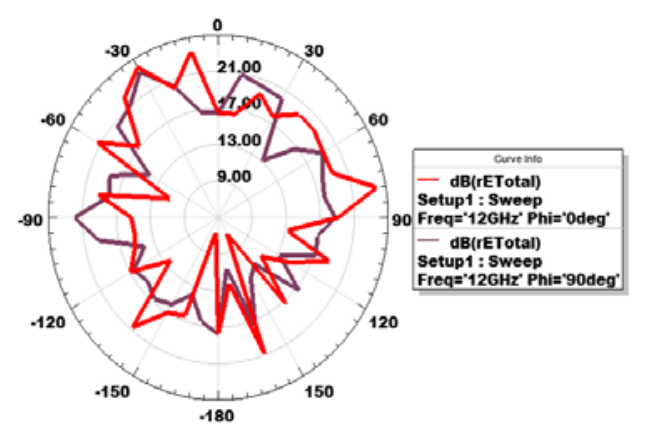

(b)

Fig. 8 Simulated Radiation Pattern of RT DuroidSubstrate at (a) 11.1 and (b) $12.0 \mathrm{GHz}$

Figure 9 depicts the simulated $\mathrm{S}_{11}$ of the antenna for TLC substrate. The antenna has three bands at 7.1, 9.6 and 10.9 $\mathrm{GHz}$ with a $\mathrm{S}_{11}$ bandwidth of about $1.40,4.16$ and $9.21 \%$ under simulation. The measured radiation pattern of the proposed antenna at 7.0, 9.6 and $10.80 \mathrm{GHz}$ is illustrated in Figure 10.

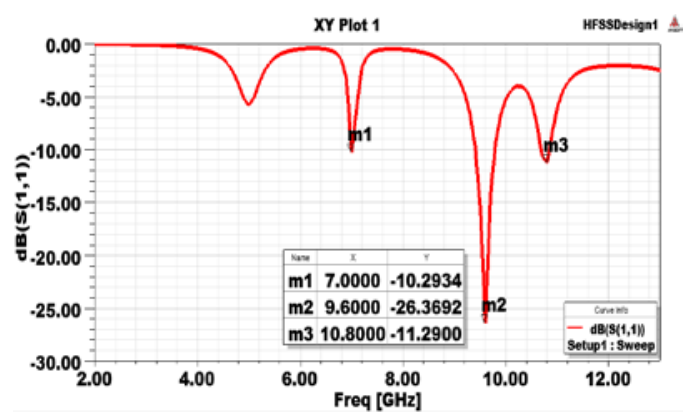

Fig. 9 Simulated Reflection Coefficient of RT Duroid Substrate 


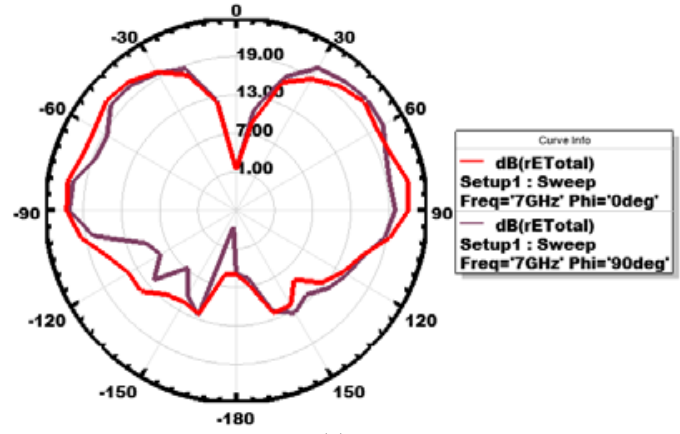

(a)

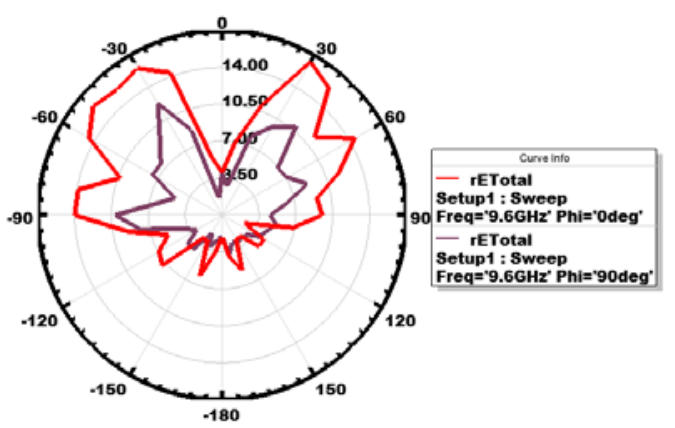

(b)

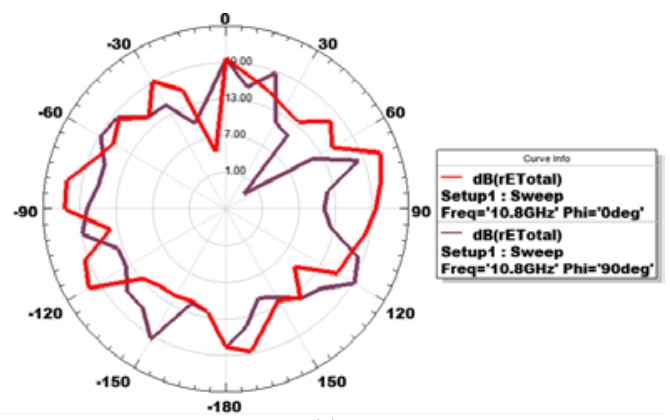

(c)

Fig. 10 Simulated Radiation pattern of TLC substrate at (a) 7.0 , (b) 9.6 and (c) $10.8 \mathrm{GHz}$

The radiation efficiency and the gain of the proposed configuration are illustrated in Figure 11 a nd 12 respectively. The proposed antenna has a $\mathrm{r}$ adiation efficiency of $68 \%$ and $60 \%$ for FR4 at 8.4 and $9.6 \mathrm{GHz}$, $96 \%$, and $96 \%$ for RT Duroid at 11.1, and $12.0 \mathrm{GHz}$ and $99 \%, 99 \%$, and $96 \%$ for Taconic at the resonant frequencies of 7.0, 9.6, and $10.8 \mathrm{GHz}$ respectively.

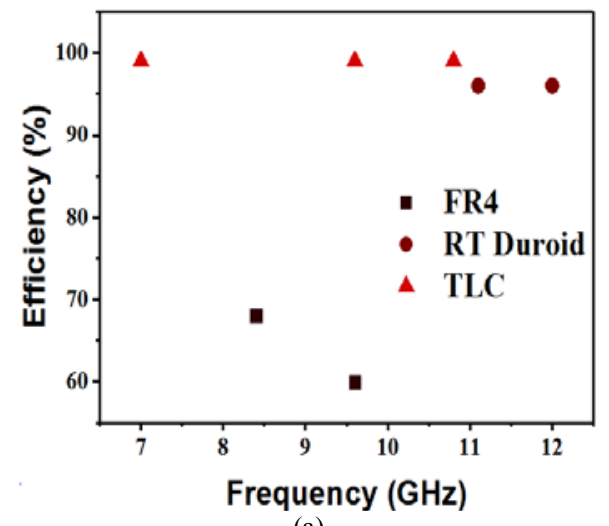

(a)

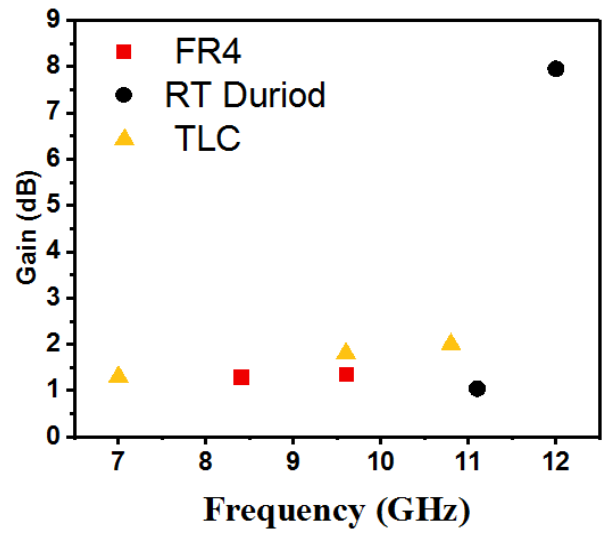

(b)

Fig. 11 Simulated results of (a) Radiation Efficiency and (b) Gain of MSPA for all the three substrates

\section{CONCLUSION}

Three unique substrates FR4, RT Duroid and Taconic, which can be utilized for the creation of MSPA, have been contemplated keeping the dimensions of the antenna as $32 \times 26 \times 1.6 \mathrm{~mm}^{3}$. Analysis of a M SA using three different substrate materials by the way of simulation is presented. The simulated results show very good performance with TLC substrate as compared to FR4 and RT Duroid by showing good radiation efficiency for all the three bands viz 7.0, 9.6 and $10.8 \mathrm{GHz}$ with the efficiency of $99 \%, 99 \%$ and $96 \%$ respectively, stable radiation patterns, gain of 1.32, 1.81 and $2.0 \mathrm{~dB}$. FR-4 produces two bands of 8.4 and $9.6 \mathrm{GHz}$ which shows a gain of 1.29 and $1.36 \mathrm{~dB}$ along with efficiency of $68 \%$ and $60 \%$ respectively with acceptable bandwidth. Its advantage is having a very low cost and can be easily available in the market. RT Duroid produces two bands of 11.1 and $12.0 \mathrm{GHz}$ with corresponding gain of 1.04 and $7.95 \mathrm{~dB}$ with the radiating efficiency of $96 \%$ each. Hence all the three substrates have been studied and simulated and it has been found that Taconic provides better radiation efficiency along with the three band operation over the other two substrates as it can be outlined. Hence it can be concluded that Taconic provides better performance with a good radiation efficiency and multiband operation. The significance of the proposed design and its comparative analysis has been done and is given in Table II.

TABle II Detailed Comparisons For All The Three Substrates

\begin{tabular}{|l|c|c|c|c|c|}
\hline Subs. Mat. & $\begin{array}{c}\text { Freq. } \\
\text { (GHz) }\end{array}$ & $\mathbf{S}_{\mathbf{1 1}}$ & $\begin{array}{c}\text { Gain } \\
(\mathbf{d B})\end{array}$ & $\begin{array}{c}\text { BW } \\
\mathbf{( \% )}\end{array}$ & $\begin{array}{c}\boldsymbol{\eta} \\
\mathbf{( \% )}\end{array}$ \\
\hline \multirow{2}{*}{ FR4 } & 8.4 & -15.81 & 1.2935 & 3.592 & 68 \\
\cline { 2 - 6 } & 9.6 & -17.771 & 1.3601 & 2.083 & 60 \\
\hline \multirow{3}{*}{ RT Duroid } & 11.1 & -17.70 & 1.0469 & 9.67 & 96 \\
\cline { 2 - 6 } & 12.0 & -21.24 & 7.9538 & 5.042 & 96 \\
\hline \multirow{3}{*}{ Taconic } & 7.0 & -10.066 & 1.3229 & 1.40 & 99 \\
\cline { 2 - 6 } & 9.6 & -17.520 & 1.8164 & 4.16 & 99 \\
\cline { 2 - 6 } & 10.8 & -10.050 & 2.0100 & 9.21 & 96 \\
\hline
\end{tabular}




\section{REFERENCES}

[1] Gopal, Er and AnkurSinghal, "Design \& Simulation of Circular Rectangular Microstrip Patch Antenna for Wireless Applications", Engineering and Technology Journal e-ISSN: 2456-3358, Vol. 3, No. 01, pp. 361-365, Jan. 2018.

[2] Mehzabin, Khadiza, AshfakUddin Reza, MdAshraful Islam and Khandoker Mohammad MominulHaque, "Design and performance analysis of rectangular microstrip patch antenna (RMPA) based on 3 different substrates at $2.5 \mathrm{GHz}$ ", In 2017 IEEE International Conference on Power, Control, Signals and Instrumentation Engineering (ICPCSI), IEEE, pp. 141-145, 2017.

[3] Kumar and K. Sunil, et al, "Rectangular Microstrip Antenna with Siva Linga Shaped Slotted for X-Band Applications", International Journal of Engineering Science, 16681, 2018.

[4] Singh, MaharanaPratap, Rahul Priyadarshi, Prashant Sharma, and Ankush Thakur, "Small size rectangular microstrip patch antenna with a cross slot using SIW", In Image Information Processing (ICIIP) Fourth International Conference on, IEEE, pp. 1-4, 2017.

[5] S. Gnanamurugan, B. Narmadha, A. Shamina and M. Sindhu, "Gain and Directivity Enhancement of Rectangular Microstrip Patch Antenna using HFSS", Asian Journal of Applied Science and Technology (AJAST), Vol. 1, No. 2, pp. 127-131, 2017.

[6] V. M. Kumar and N. Sujith, "Enhancement of bandwidth and gain of a rectangular microstrip patch antenna", Department of Electronics and Communication Engineering, National Institute of Technology, Rourkela, 2010.

[7] P. K. Sharma, M. Purohit and P. Vyas, "Design, implementation and performance analysis of annular ring microstrip patch antenna for $\mathrm{S}$ band application", In 2017 IEEE International Conference on Power, Control, Signals and Instrumentation Engineering (ICPCSI), IEEE, pp. $475-478$, Sept. 2017.

[8] S. D. Mahamine, R. S. Parbat, S. H. Bodake and M. P. Aher, "Effects of different substrates on Rectangular Microstrip patch Antenna for S-band", In Automatic Control and Dynamic Optimization Techniques (ICACDOT), International Conference, IEEE, pp. 11421145, Sept. 2016.
[9] A. Iqbal, F. R. Sani, Z. Ullah, M. I. Khattak, M. A. Khattak, N. Saqib and H. Masood, "Comparative study of micro strip patch antenna for $\mathrm{X}$ band using micro strip line feed and coaxial feed", In Engineering and Emerging Technologies (ICEET), 2018 International Conference, IEEE, pp. 1-6, Feb. 2018.

[10] L. C. Paul, M. S. Hosain, S. Sarker, M. H. Prio, M. Morshed and A. K. Sarkar, "The Effect of Changing Substrate Material and Thickness on the Performance of Inset Feed Microstrip Patch Antenna", American Journal of Networks and Communications, Vol. 4, No. 3, pp. 54-58, 2015.

[11] Khan, D. Geetha, K. R. Sudhindra and K. Fakhruddin, "Review of Microstrip Patch Antennas for Bandwidth Improvement", International Journal of Electrical Electronics \& Computer Science Engineering, Special Issue - NEWS 2016 | E-ISSN: 2348-2273 | PISSN: 2454-1222, pp. 15-19, [Online] Available at www.ijeecse.com.

[12] Khan, K. R. Sudhindra, D. Geetha and K. Fakhruddin, "LCP substrate based micro strip patch antenna", In Electrical, Electronics, Communication, Computer and Optimization Techniques (ICEECCOT), 016 International Conference, IEEE, pp. 127-131, Dec. 2016.

[13] Imran Khan, K. R. Sudhindra, D. Geetha, Tanweer Ali and R. C. Biradar, "A Frequency Reconfigurable Antenna loaded with $\mathrm{H}-$ shaped Radiators for WLAN/WiMAX Applications", International Journal of Applied Engineering Research, ISSN 0973-4562, Vol. 13, No. 10, pp. 8583-8587, 2018 C Research India Publications, [Online] Available at $\mathrm{http}: / / \mathrm{www}$. ripublication.com

[14] Imran Khan, D. Geetha, K. R. Sudhindra, K. M. Vandana and K. J. Nagashri, "Comparative analysis of a $30 \times 30 \times 1.6 \mathrm{~mm} 3$ MSPA Antenna Loaded with Circular Patch using FR4, RT Duroid and Taconic", (C) 2018 JETIR (ISSN-2349-5162), Vol. 5, No. 8, August 2018, [Online] Available at www.jetir.org.

[15] Imran Khan, D. Geetha, Gunjal, Raksha and Rashmitha, "Review of MSP Antenna Design for Various Substrates", August 14, 2018, [Online] Available: ASSRN: https://ssrn.com/abstract=3230632 or http://dx.doi.org/10.2139/ssrn.3230632. 